Bates College

SCARAB

$1-24-2018$

\title{
Assessing Conservation Adoption Decision Criteria Using the Analytic Hierarchy Process: Case Studies from Three Midwestern Watersheds
}

\author{
Ajay S. Singh \\ Francis R. Eanes \\ Bates College, feanes@bates.edu \\ Linda S. Prokopy
}

Follow this and additional works at: https://scarab.bates.edu/faculty_publications

\section{Recommended Citation}

Singh, A.S., F.R. Eanes, and L.S. Prokopy. (2018). Assessing conservation adoption criteria using the Analytic Hierarchy Process: case studies from three Midwestern watersheds. Society \& Natural Resources. 31(4), 503-507; doi: 10.1080/08941920.2017.1413694

This Article is brought to you for free and open access by the Departments and Programs at SCARAB. It has been accepted for inclusion in All Faculty Scholarship by an authorized administrator of SCARAB. For more information, please contact batesscarab@bates.edu. 
Assessing conservation adoption decision criteria using the analytic hierarchy process: Case studies from three Midwestern watersheds

\author{
Ajay S. Singh ${ }^{1,3}$, Francis R. Eanes ${ }^{2,3}$, and Linda S. Prokopy ${ }^{3}$ \\ ${ }^{1}$ Department of Environmental Studies, California State University at Sacramento \\ ${ }^{2}$ Program in Environmental Studies, Bates College \\ ${ }^{3}$ Department of Forestry and natural Resources, Purdue University
}

\begin{abstract}
:
Land use changes from natural ecosystems to industrial agriculture have impacted water quality and wildlife populations in the Mississippi River basin. Government programs providing technical assistance and monetary incentives have not resulted in adequate adoption rates of conservation practices. While there has been a plethora of research examining the factors associated with conservation adoption, significantly less is understood about the relative importance of these factors. Using the Analytic Hierarchy Process (AHP) with agricultural producers in three Midwestern watersheds, we assess the relative importance of environmental and production decision criteria when making decisions to adopt conservation practices. While AHP provides insight into how decisions may be made at the watershed scale, this methodology also provides insight into how individuals make conservation decisions and may also provide a method for delivering tailored conservation advice and communications.
\end{abstract}

\title{
Recommended Citation:
}

Singh, A.S., F.R. Eanes, and L.S. Prokopy. (2018). Assessing conservation adoption criteria using the Analytic Hierarchy Process: case studies from three Midwestern watersheds. Society \& Natural Resources. 31(4), 503-507; doi: 10.1080/08941920.2017.1413694 


\section{Introduction}

Agriculture's impact on the environment is well documented with both local impacts (e.g. diminished soil health) and downstream impacts (e.g. dead zone in the Gulf of Mexico). Motivating agricultural producers to adopt environmentally-friendly practices is difficult and many studies have tried to identify factors associated with practice adoption but have failed to find many consistent motivators (e.g. Prokopy et al. 2008; Baumgart-Getz et al. 2012). Agricultural decisions, including those associated with conservation practices, are often marked by complexity, uncertainty, and/or conflicting goals. The Analytic Hierarchy Process (AHP) is a multi-criteria decision making (MCDM) methodology that allows individuals to assess the relative importance of factors associated with these sorts of complex decisions. The AHP draws on theories from psychology and mathematics to enable the systematic assessment, evaluation, and analysis of the relative importance of priorities, criteria, or outcomes that influence decisionmaking (Saaty 1977). Comparison of multiple priorities allows for the development of dominance matrices and relative weights given to each priority.

The AHP has been applied to a wide variety of research disciplines including business, economics, health care, urban and regional planning, engineering, mathematics, technology development, transportation, and natural resource management (Saaty 2001). In natural resources management, the AHP has been used to evaluate integrated watershed management projects (e.g. Qiu, 2006); protected and/or conservation areas (e.g. Kangas 1994); environmental impacts of natural resource extraction (e.g. Poveda and Lipsett 2013); and agriculture (e.g. Montazar and Gaffari 2011; Ramirez-Garcia et al. 2015). Previous research using the AHP has focused on its application by a single user (Mendoza and Martins 2006); however, natural resources management, planning, and policy decisions are not always made by one person. Engaging multiple stakeholders may require more time/resources (e.g. Kangas 1994), but may result in more representative, higher quality decisions (Beierle 2002). Mendoza and Martins (2006) note that recent applications of MCMD approaches to natural resource management have included more stakeholder-driven approaches. While there has been an increase in the use of AHP in the agricultural and natural resources literature, there have been no published examples that address farmer adoption of conservation practices nor examples that compare AHP results among multiple locations. The purpose of this note is to present results from applying the AHP with 
farmers in three Midwestern watersheds using a non-iterative methodology, and to offer guidance for subsequent uses of the AHP in natural resources management.

\section{Methods and Materials}

To test the applicability of AHP to a non-iterative, multiple stakeholder context, we used the AHP to understanding the relative importance of priorities related to adoption of conservation practices. We conducted interviews with farmers in three watersheds in Iowa (Lime Creek - HUC 070200090101), Indiana (Big Creek - HUC 051201131100), and Michigan (Saginaw Bay - HUC 04080206). Lime Creek and Big Creek watersheds flow into the Mississippi River Basin and are in regions of high nitrogen runoff contributing to Gulf Hypoxia. The Saginaw Bay watershed is adjacent to Lake Huron and has increasing phosphorous runoff contributing to toxic algal blooms. Agriculture is the dominant land use in all three watersheds, and the majority of farms produce corn and soybeans , and all are listed as an Area of Concern but the US EPA. In all watersheds there are ongoing efforts to address water quality issues through projects and programs by watershed groups, non-profits, and state and federal agencies. All watersheds are primarily rural and, with the exception of Saginaw Bay, contain no urban areas with populations greater than 10,000 residents. Farmers were identified through the Farm Services Agency, Extension, Soil and Water Conservation Districts, or watersheds groups.

Interviews pertained to farmers' perceptions of water quality issues and willingness to adopt conservation practices. At the end of the interviews, farmers completed a series of pairwise comparisons that asked them to make tradeoffs between seven conservation priorities, including decreasing net costs of their operation, decreasing fertilizer losses, decreasing flooding, decreasing erosion losses, increasing biodiversity, and decreasing risks associated with climate change. The relative importance of each priority in a pairwise comparison was measured by a continuous 17-point bipolar scale (Saaty 1977; see supplementary materials for an example). To create a hierarchy of priorities, pairwise comparisons were summarized as ratios in a matrix of $n$ $\mathrm{x} \mathrm{n}$ (the number of priorities) whereby rows and columns are reciprocals of each other (e.g. 3; 1/3). A standardized matrix was created by taking each ratio and dividing it by the sum of ratios. Decision weights for each priority were generated by taking the average of the standardized ratios. To assess the level of consistency among pairwise comparisons, a consistency index was created by summing the product of the multiplication of standardized ratios by the corresponding 
decision weight. A consistency ratio (CR) was then created by averaging the sum of rows of the consistency index (Lambda), dividing Lambda by decision weights (Lambda max), dividing the average of all Lambda max by the number of priorities minus 1, and then dividing that product by the probability that pairwise comparisons were made by chance. An example of how to conduct an AHP is described in the supplementary materials.

\section{Results}

We conducted 44 semi-structure interviews with farmers in the Big Creek watershed ( $\mathrm{n}=$ 16) between March-April, 2015, Lime Creek watershed $(n=15)$ in February, 2016, and the Saginaw Bay watershed $(n=13)$ between July-September, 2016. Because we were interested in which priority took precedence at the watershed level, we present decision weights and consistency ratios by watershed; however, additional analyses can also be conducted at the individual level.

A graphical representation of the mean and range of decision weights from individuals in each watershed is provided in Figure 1 (whiskers represent the fourth quartile and there are no outliers). Farmers in Big Creek watershed weighted the reduction of soil erosion (0.31) more than other criteria, followed by reducing fertilizer loss (0.19), reducing net costs $(0.17)$, and reducing flooding (0.15). Reducing risks of climate change (0.1) and increasing biodiversity (.07) were weighted the least. The average CR for Big Creek watershed was 0.23 with a range of 0.046 to 1.09. Farmers in the Lime Creek watershed weighted the reduction of soil erosion (0.25) highest, followed by reducing net costs $(0.23)$, reducing fertilizer loss $(0.18)$, reducing flooding (0.12), increasing biodiversity (.12), and reducing risks of climate change (0.08). The average CR for Lime Creek watershed was 0.28 with a range of 0.0002 to 0.93 . Farmers in the Saginaw Bay watershed also weighted reducing soil erosion (0.29) more than other criteria, followed by reducing fertilizer loss $(0.18)$, increasing biodiversity (.17), reducing flooding (0.14), reducing net costs $(0.13)$, and reducing risks of climate change (0.07). The average CR for Saginaw Bay watershed was 0.13 with a range of 0.031 to 0.205 . 


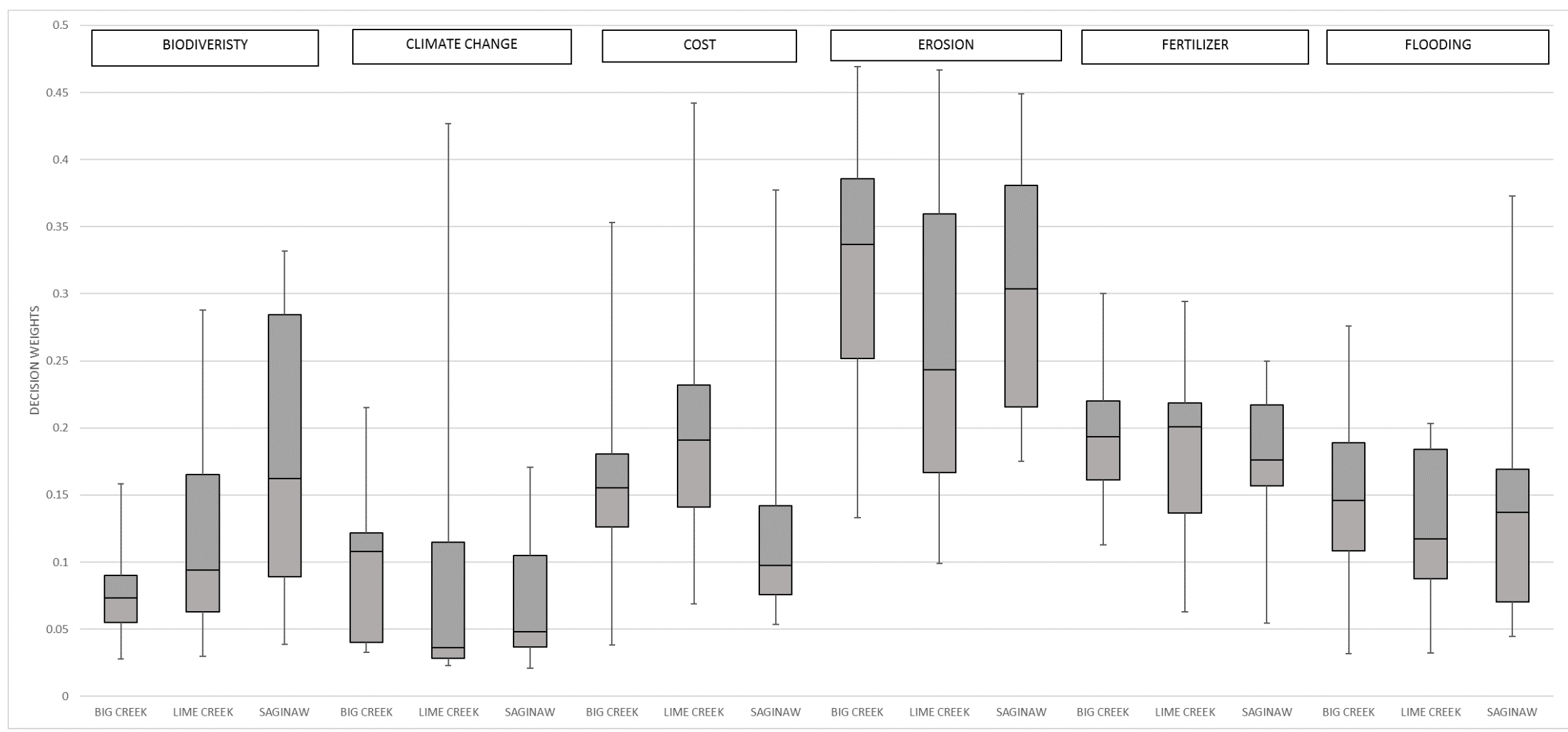

Figure 1. Mean and range of decision weights from individuals in the three study area watersheds. 


\section{Discussion and Conclusion}

While patterns in decision weights given to each priority are evident at the watershed level (e.g. soil erosion is given priority in all watersheds) there are outliers for each decision criteria indicating that motivations for adopting conservation practices are dependent on the individual producer. This points towards a need for tailored conservation communications and advice, both of which AHP can help elicit at both the individual and watershed scale in agriculturally dominated landscapes. While these results demonstrate the usefulness of the AHP in illuminating farmers' conservation decision making priorities, we noted three challenges with our application of the methodology. First, the AHP literature specifies that if a CR is more than 0.10 , the user should conduct another iteration of the pairwise comparisons. However, Saaty (2005) recognizes the fact that an individual can reach a decision without clear or consistent priorities. Second, during the interview, interviewees indicated that they did not view their farm through the lens of discrete priorities, but rather as a system whereby priorities are interrelated. For example, reducing fertilizer loss, erosion, and decreasing net costs were perceived by farmers as highly related. AHP is designed to produce a hierarchy of discrete priorities in order to evaluate different actions (e.g. conservation practices). If there is no meaningful hierarchy or discreteness between criteria, then the process may not provide clear guidance. Third, farmers may be unfamiliar with AHP and thus may not have a clear idea of, or investment in, the outcome of the process.

While the foregoing issues must be addressed for subsequent research applications, AHP as a methodology lends insight into the relative importance of priorities that may motivate conservation behaviors, and potentially provides a means of delivering customized conservation advice and information to farmers. Maximizing this potential, however, depends upon addressing the issues we identified. First, to address CR thresholds, we suggest using sensitivity analyses to develop a range of acceptable CRs, much like effect sizes (strong, medium, weak), rather than just a single, arbitrary threshold (0.1). Second, if an individual's response is so inconsistent that pairwise comparisons could have been made by chance, we propose not using that individual's response when gauging priorities at the watershed level. To address issues of discreteness and familiarity, we propose the development of a participatory "in-the-field" method whereby participants could iteratively create their input criteria and conduct an analysis using a mobile- or 
web-based platform. Engaging participants throughout the process, including co-developing the goals of the process, would increase the AHP's transparency and perceived utility, and therefore increase participants' investment in the process's outcome. 


\section{References}

Baumgart-Getz, A., Prokopy L.S., and Floress K. 2012. Why farmers adopt best management practice in the United States: a meta-analysis of the adoption literature. Journal of environmental management 96(1), 17-25.

Beierle, T. C. 2002. The quality of stakeholder-based decisions. Risk analysis, 22(4), 739-749.

Kangas, J. 1992. Multiple-use planning of forest resources by using the analytic hierarchy process. Scandinavian Journal of Forest Research, 7(1-4), 259-268.

Kangas, J. 1994. An approach to public participation in strategic forest management planning. Forest ecology and management, 70(1), 75-88.

Mendoza, G. A., and Martins, H. 2006. Multi-criteria decision analysis in natural resource management: a critical review of methods and new modelling paradigms. Forest ecology and management, 230(1), 1-22.

Montazar, A., and Gaffari, A. 2012. An AHP model for crop planning within irrigation command areas. Irrigation and Drainage, 61(2), 168-177.

Poveda, C. A., and Lipsett, M. G. 2013. Weighting sustainable development indicators (SDIs) for surface mining operations using the analytical hierarchy process (AHP). International Journal of the Analytic Hierarchy Process, 5(2).

Prokopy, L.S., Floress K., Klotthor-Weinkauf, D., and Baumgart-Getz, A. 2008. Determinants of agricultural best management practice adoption: evidence from the literature. Journal of Soil and Water Conservation 63(5), 300-311.

Qiu, Z. 2006. Multi-criteria decision analysis for integrated watershed management. In G.

Herath and T. Prato (Eds.), Using multi-criteria decision analysis in natural resource management (93-118). Burlington: Ashgate.

Ramírez-García, J., Carrillo, J. M., Ruiz, M., Alonso-Ayuso, M., and Quemada, M. 2015.

Multicriteria decision analysis applied to cover crop species and cultivars selection. Field Crops Research, 175, 106-115. 
Saaty, T. L. 1977. A scaling method for priorities in hierarchical structures. Journal of mathematical psychology 15(3), 234-281.

Saaty, T. L. 1990. How to make a decision: the analytic hierarchy process. European journal of operational research, 48(1), 9-26.

Saaty. T.L. 2001. Fundamentals of the analytic hierarchy process. In The analytic hierarchy process in natural resource and environmental decision making. Schmoldt. D.L.. Kangas. J. Mendoza. G.A. \& Pesonen. M. (Eds). Netherlands: Kluwer Academic Publishers. 